\title{
Intratendinous tears of the Achilles tendon - a new pathology? Analysis of a large 4-year cohort
}

\author{
Otto Chan' \\ Sarah Morton ${ }^{2}$ \\ Mel Pritchard ${ }^{1}$ \\ Tina Parkes ${ }^{1}$ \\ Peter Malliaras $^{2}$ \\ Tom Crisp ${ }^{1,2,3}$ \\ Nat Padhiar ${ }^{1,2}$ \\ Nicola Maffulli ${ }^{1}$ \\ John King ${ }^{1,2}$ \\ Dylan Morrissey 1,2,3
}

1 BMI London Independent Hospital, London, UK

2 Centre for Sports and Exercise Medicine, William

Harvey Research Institute, Queen Mary University

of London, Mile End Hospital, London, UK

3 Bart's Health NHS Trust, London, UK

Corresponding author:

Dylan Morrissey

NIHR/HEE Consultant Physiotherapist and Clinical

Reader Sports and Exercise Medicine,

William Harvey Research Institute,

Queen Mary University of London,

Mile End Hospital, Bancroft Road,

London, E1 4DG, UK

E-mail: d.morrissey@qmul.ac.uk

\section{Summary}

Background: Achillodynia is common and includes Achilles tendinopathy, partial Achilles tears and Achilles tendon ruptures. However, we believe an additional pathology should be considered for Achillodynia differentials - the intratendinous tear (ITT).

Methods: Examinations of 740 achillodynic patients in one specialist centre were reviewed. ITTs were defined as a clearly visualised echopoor area situated centrally and extending to, but not through the tendon periphery, with pain on palpation and no clinical findings consistent with Achilles rupture. Descriptive statistics were used to analyse differences between pathological sub-groups, and images described qualitatively.

Results: 5\% (29 males, 8 females) of 740 patients had an ITT. Patients typically presented with a history of sudden onset localised pain and the ability to train but not reach maximal loading. Average age was 36.3 years (range $20-64$ ), significantly lower than mid-tendon tendinopathy (8.48 years; $p<0.01)$. $92 \%$ had concurrent Achilles tendinopathy. Elite sportspeople were more highly represented in the ITT than mid-tendon tendinopathy groups (86.2\% ITT group vs $13.8 \%$ mid-tendon AT group; $p<0.01$ ).

Conclusions: ITTs should be actively searched for in patients with Achilles pathology, especially in elite male athletes with a history of high-impact pain. Prospective research is warranted concerning diagnosis and management.

Level of evidence: IV.

KEY WORDS: Achilles tendon, intratendinous tear, Achilles tendinopathy, ultrasound.

\section{Introduction}

The Achilles tendon is reported to be the most commonly injured tendon in the body ${ }^{1}$. The two main intratendinous pathologies reported in the literature regarding the Achilles tendon are Achilles tendinopathy and Achilles rupture ${ }^{2}$. The most common disorder is recognised to be mid-substance Achilles tendinopathy, with the underlying mechanism being somewhat disputed in terms of the presence or absence of an inflammatory component ${ }^{2-5}$. It is reported that Achilles tendon disorders can affect any adult whether sedentary or involved in sport but it typically has higher prevalence in those who participate in high impact lower limb sports ${ }^{1,2}$.

Tendon rupture usually occurs during running, jumping or sudden explosive activities ${ }^{2}$. Histology of Achilles tendon ruptures has shown that there is nearly always an underlying pathology in the tendon prior to rupture ${ }^{6}$. There are also reports in the literature of partial thickness tendon tears ${ }^{7,8}$, with patients tending to present with a localised area of medial thickening of the Achilles tendon ${ }^{9}$. Achilles tendinopathies are sometimes complicated by the presence of a partial tear ${ }^{10}$. On ultrasound, partial tears present with discontinuity of tendon fibres, focal hypoechoic areas and localised swelling, with the commonest position of tears identified as $3-4 \mathrm{~cm}$ above the superior calcaneus ${ }^{11,12}$. A recent study showed that a partial tear was most likely to be a disrupted dorsal tendon (skin side), associated with neo-vascularisation and located in the posterior midtendon ${ }^{13}$.

A fascia cruris tear of the Achilles tendon has been recently described and typically presents with a sudden 
increase of pain, again often with co-existing Achilles tendinopathy ${ }^{14}$. Other differentials include the presence of plantaris tendinopathy, a plantaris invaginated into the Achilles and paratenonitis. From this it appears that our understanding of the Achilles tendon and its surrounding structures is improving and improved imaging techniques are allowing us to establish the cause of Achillodynia more accurately.

Recent observations at our specialist sports medicine centre suggest that an additional pathology should be added to the current list of differentials: an intratendinous tear (ITT). This differs ultrasonographically from a partial tear, as it is an area of tendon discontinuity entirely within, and not extending through the periphery of the tendon, with pain on palpation and is therefore likely to require different management. Two previous papers briefly mention an ITT as a feature of Achilles tendinopathy on ultrasound and magnetic resonance imaging (MRI) but do not define it ${ }^{15,16}$. Haims et al. (2000) reported that $64 \%$ of the tears seen within the Achilles tendon, in a combination of both symptomatic and asymptomatic tendons, were an "interstitial tear", although the definition of this remains unclear ${ }^{16}$.

The use of ultrasound (US) imaging in Achilles pathology has been found to be useful when the pathology is not clear ${ }^{2}$. It has the advantage over MRI in that it allows dynamic assessment, better spatial resolution, evaluation of tissue neovascularisation, measurement of tendon thickness and easy follow-up ${ }^{2,3}$. This study therefore reports the findings of ITTs diagnosed over a 4-year period, including US findings, clinical symptoms and its relationship to other Achilles pathologies with the aim of enabling assessing clinicians to identify these patients early and optimise their management accordingly.

\section{Materials and methods}

The US reports and images of all patients who had Achilles tendons scanned for Achillodynia between July 2008 and September 2012 at The London Independent Hospital were reviewed. The patients were referred to the tertiary centre from a variety of sources including sports medicine clinics, team physicians, orthopaedic surgeons and physiotherapists. The majority of patients had previously received some form of conservative therapy for presumed Achilles tendinopathy, mainly physiotherapy, but no operative management. No patients had previously any intratendinous treatment of any kind as it is recognised that this could distort radiological findings. Ethical approval was obtained from Queen Mary, University of London Ethics Committee. The ethical standards of the Journal were met ${ }^{17}$.

\section{Ultrasound imaging}

All US scanning of the Achilles tendons was carried out by one specialist MSK consultant radiologist (OC) using the same ultrasound scanner throughout (Ele- gra; Siemens, Erlangen Germany). A $13 \mathrm{MHz}$ transducer was used along with power Doppler imaging. The radiologist was not blinded to the side of the symptoms. The subjects were positioned in long sitting with their hips flexed and externally rotated, their knees in $90^{\circ}$ flexion and their ankles in a neutral position. Longitudinal and transverse static and video images were obtained for both Achilles. The shape of the Achilles tendon was recorded as either parallel or spindle shaped. The antero-posterior tendon diameter was measured at the thickest point. This measurement has been shown to be reliable ${ }^{18}$. Neovascularisation was graded using the Modified Ohberg scale, known to be weakly related to the clinical severity of Achilles tendinopathy ${ }^{19,20}$. The combination of the tendon diameter and neovascularisation was used for the sonographic diagnosis of Achilles tendinopathy. If an ITT was observed then descriptive data for the tear were recorded, including position in the tendon, shape of tear, size and direction of the tear and neovascularisation pattern at the ITT. It is appreciated that sonographic changes are not always symptomatic, as shown in elite ballet dancers, and this was taken into account in the results ${ }^{21}$.

Subjects referred with Achillodynia were categorised into six groups based on the ultrasound findings: no pathology detected on US (normal Achilles tendons), mid-tendon AT, insertional AT, partial tears (with or without AT), Achilles ruptures and ITTs (with or without AT). An ITT was defined as a clearly visualised echopoor area on US situated centrally in the tendon or extending to, but not through, the periphery of the tendon. This ultrasound finding corresponded to the area of maximal tenderness on palpation of the tendon. In addition, there were no clinical findings consistent with an Achilles rupture, for example there was a negative Simmonds squeeze test. The site of maximum tenderness has previously been shown to correspond to the site of maximum pathology in Achilles tendinopathy, and this was also reported by the radiologist (but not formally measured or statistically tested) in the patients with ITTs ${ }^{22}$. The ITT also differs from a partial tear in that the latter extends through the peripheral edge of the tendon but with some intact fibres, or a rupture in which there is no continuity of fibres - each of which present with commensurate clinical signs such as a positive Simmonds test. Data was extracted from the US images, reports and medical notes including age, gender and level of sport participated in (no sport, sport played as amateur or elite sport).

\section{Statistics}

All subjects were allocated a code to ensure confidentiality and anonymity. Data was analysed using SPSS (version 20, IBM, UK). Descriptive statistics were calculated; Fisher's exact test, the one-way ANOVA with a post-hoc Tukey test and the Chi Square-Test were used to analyse statistical differences between groups defined by pathology diagnosis. Images were also described qualitatively. 
Table I. Characteristics of subjects.

\begin{tabular}{|c|c|c|c|c|c|c|}
\hline & $\begin{array}{l}\text { No pathology } \\
\text { present on } \\
\text { ultrasound }\end{array}$ & $\begin{array}{l}\text { Mid-tendon } \\
\text { tendinopathy }\end{array}$ & $\begin{array}{l}\text { Insertional } \\
\text { tendinopathy }\end{array}$ & $\begin{array}{l}\text { Partial tear } \pm \\
\text { tendinopathy }\end{array}$ & $\begin{array}{l}\text { Full tearl } \\
\text { tendon } \\
\text { rupture }\end{array}$ & $\begin{array}{l}\text { Intratendinous } \\
\text { tear } \pm \\
\text { tendinopathy }\end{array}$ \\
\hline Number of subjects & 205 & 406 & 9 & 61 & 22 & 37 \\
\hline Average age $\pm S D$ & $42.2 \pm 11.3$ & $44.6 \pm 10.6$ & $36.2 \pm 9.7$ & $41.7 \pm 12.3$ & $48.1 \pm 17.1$ & $36.3 \pm 12.2$ \\
\hline Sex (male: female) & 154: 51 & 309: 97 & 7: 2 & 49: 12 & $17: 5$ & $29: 8$ \\
\hline $\begin{array}{l}\text { Side affected (left: } \\
\text { right) }\end{array}$ & 96: 109 & 199:205 & $4: 5$ & $35: 26$ & 14: 8 & $20: 17$ \\
\hline $\begin{array}{l}\text { Level of sport (none: } \\
\text { recreational: elite) }\end{array}$ & $\begin{array}{c}\text { 69: } 97: 39 \\
33 \%: 47 \%: 20 \%\end{array}$ & $\begin{array}{c}\text { 164: } 186: 56 \\
40 \%: 46 \%: 14 \%\end{array}$ & $\begin{array}{c}3: 4: 2 \\
33 \%: 44 \%: 22 \%\end{array}$ & $\begin{array}{c}\text { 16: } 24: 21 \\
26 \%: 39 \%: 34 \%\end{array}$ & $\begin{array}{c}14: 7: 1 \\
63 \%: 32 \%: 5 \%\end{array}$ & $\begin{array}{c}3: 9: 25 \\
8 \%: 24 \%: 68 \%\end{array}$ \\
\hline $\begin{array}{l}\text { Mean size of tendon } \\
(\mathrm{mm}) \pm \mathrm{SD} \\
{[\text { Data unavailable] }}\end{array}$ & $\begin{array}{c}5.92 \pm 1.28 \\
{[34]}\end{array}$ & $\begin{array}{c}8.31 \pm 2.30 \\
{[22]}\end{array}$ & $\begin{array}{c}5.60 \pm 1.03 \\
{[6]}\end{array}$ & $\begin{array}{c}9.15 \pm 2.76 \\
{[9]}\end{array}$ & $\begin{array}{c}9.95 \pm 5.3 \\
{[18]}\end{array}$ & $8.85 \pm 2.33$ \\
\hline $\begin{array}{l}\text { Mean } \\
\text { neovascularisation } \\
\text { grade' } \\
\text { [Data unavailable] }\end{array}$ & $\begin{array}{c}0.3 \pm 0.5 \\
{[2]}\end{array}$ & $\begin{array}{c}2.3 \pm 1.5 \\
{[13]}\end{array}$ & $\begin{array}{c}3.2 \pm 1.7 \\
{[3]}\end{array}$ & $\begin{array}{c}2.4 \pm 1.7 \\
{[4]}\end{array}$ & $\begin{array}{c}0.6 \pm 1.1 \\
{[4]}\end{array}$ & $2.4 \pm 1.6$ \\
\hline
\end{tabular}

I: Ohberg L, Lorentzon R, Alfredson H. Neovascularisation in Achilles tendons with painful tendinosis but not in normal tendons: an ultrasonographic investigation. Knee Surgery Sports Traumatology Arthroscopy. 2001;9:233-238.

Table II. Tear characteristics.

\begin{tabular}{|c|c|}
\hline $\begin{array}{l}\text { Width of tear mean } \pm \mathrm{SD}(\mathrm{mm}) \\
\text { [Data unavailable] }\end{array}$ & $\begin{array}{l}2.85 \pm 2.23 \\
{[1]}\end{array}$ \\
\hline $\begin{array}{l}\text { Length of tear mean } \pm \mathrm{SD}(\mathrm{mm}) \\
\text { [Data unavailable] }\end{array}$ & $\begin{array}{l}10.61 \pm 8.84 \\
{[1]}\end{array}$ \\
\hline $\begin{array}{l}\text { Shape of tear (oval: linear) } \\
\text { [Data unavailable] }\end{array}$ & $\begin{array}{l}22: 14 \\
{[1]}\end{array}$ \\
\hline $\begin{array}{l}\text { Direction of tear (longitudinal: transverse to insertion: transverse in mid-portion of tendon) } \\
\text { [Data unavailable] }\end{array}$ & $\begin{array}{l}28: 1: 6 \\
{[2]}\end{array}$ \\
\hline $\begin{array}{l}\text { Sagittal position (medial to midline: midline: lateral to midline) } \\
\text { [Data unavailable] }\end{array}$ & $\begin{array}{l}14: 15: 7 \\
{[1]}\end{array}$ \\
\hline $\begin{array}{l}\text { Coronal position (anterior: central: posterior: throughout) } \\
\text { [Data unavailable] }\end{array}$ & $\begin{array}{l}17: 8: 7: 4 \\
{[1]}\end{array}$ \\
\hline Bilateral tear: unilateral tear & $1: 36$ \\
\hline
\end{tabular}

\section{Results}

Seven hundred and forty bilateral Achilles tendon ultrasound scans were completed on patients with Achillodynia between July 2008 and September 2012. Only one bilateral ITT was reported. Due to one side being asymptomatic at the time of presentation this side was not included in the results and only symptomatic results were included. There was essentially no difference in the side affected (20 left vs 16 right) nor the shape of the tendon (21 spindle vs 16 parallel). The patient characteristics are demonstrated in Table I. Any unavailable data sets are detailed:

All tears were positive to palpation at the main site of the tear. The ITTs varied in shape, size and position. The characteristics of the tears are shown in Table II and Figure 1.

The ITT often presented with concurrent tendinopathy. Table III details the relationships between the Achilles tendon, Achilles tendinopathy and ITTs in tears of co-presentation.

Fisher's exact test showed the ITT group to be competing at a higher level $(p<0.01)$ compared to those with mid-tendon tendinopathy and were compared for the level of sport played $(13.8 \%$ elite in tendinopathy group versus $86.2 \%$ non-elite; $67.6 \%$ elite in ITT group versus $32.4 \%$ non-elite). The ITT group also comprised of more men than women compared to the 


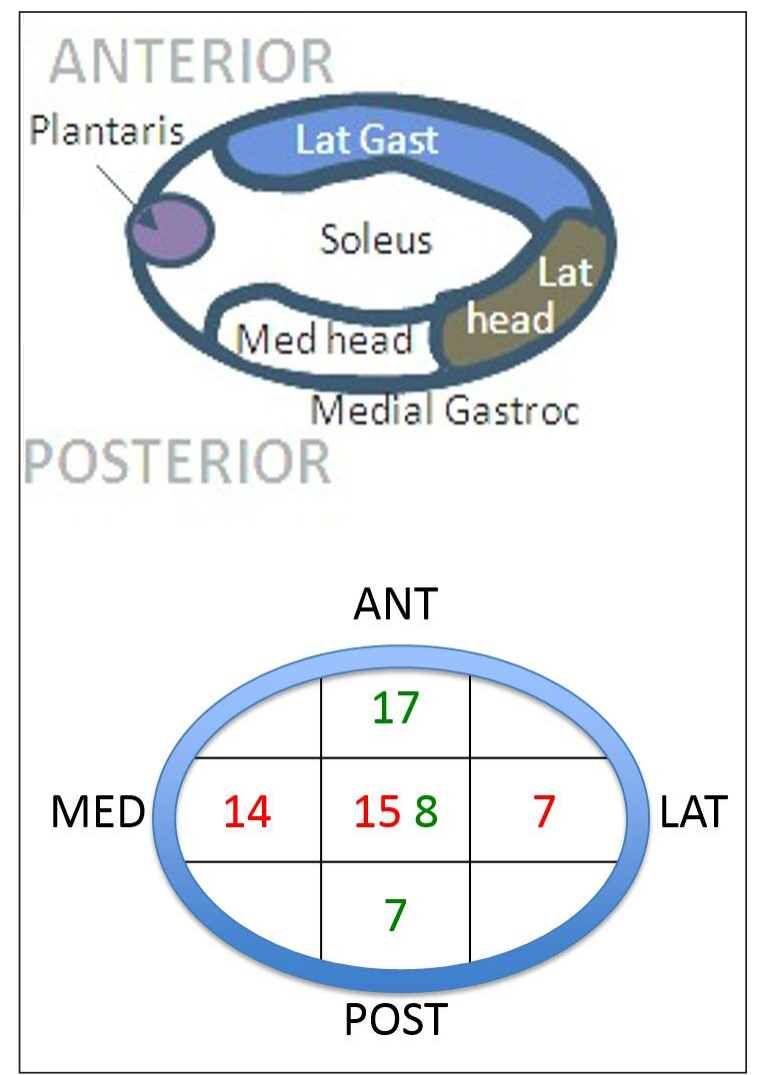

Figure 1. Position of the tears within the tendon. Green text $=$ coronal position of tear within tendon. Red text = sagittal position of tear within tendon.

mid-tendon Achilles tendinopathy group $(p<0.01)$. The one way ANOVA and post-hoc Tukey test showed the ITT group was younger than: the mid-tendon tendinopathy $(8.48 ; p<0.01)$; no pathology $(5.81 ; p<0.05)$ and full tear groups $(11.74 ; p<0.01)$. The images below depict the different types of an ITT on ultrasound (Figs. 2, 3) along with comparisons to a partial tear (Fig. 4) and a tendinopathic tendon (Fig.
5). Figure 6 depicts a small $5 \mathrm{~mm}$ oval intratendinous tear in the left Achilles on ultrasound with its associated MRI scan and a comparative normal right Achilles tendon from the same patient study. MRI may be an additional imaging tool helpful in the diagnosis of an ITT.

\section{Discussion}

Our study found that $5 \%$ of 740 scanned subjects had an intratendinous tear (ITT), and these tended to be in male, elite athletes at a younger age than most other common Achillodynic presentations. There was a strong, but incomplete, association with mid-tendon tendinopathic presentation but this was not always present. The patients presented with a typical description of pain, including the inability to train at their maximum.

The limitations of this case series are acknowledged, as they need to be with any retrospective analysis, including the review of US images and lack of surgical correlation, and prospective analysis in various centres is now required to develop the observational reports in this paper, alongside consideration of optimal treatment methods.

\section{Tear characteristics}

The majority of ITTs were in the longitudinal direction of the tendon $(75.7 \%)$. Fifty nine percent were oval and $41 \%$ were linear in shape. The average width of the tear was $2.85 \pm 2.23 \mathrm{~mm}$, whereas the average length of the tear was $10.61 \pm 8.84 \mathrm{~mm}$, corresponding to the observation that the majority of tears were in a longitudinal direction. Tear positions varied, but tended to be anterior or midline (deep) rather than posterior, and medial or midline rather than lateral - differing from previous reports of small partial tears. Soila et al. (1999) found that more dorsal tendon fibres originate from the medial gastrocnemius and the soleus fibres are more ventral and extended this work further in 200923. Therefore, extrapolating from this, we believe the majority of ITTs we describe here are

Table III. Pathology characteristics.

\begin{tabular}{|c|c|}
\hline Shape of tendon on US (spindle: parallel) & $21: 16$ \\
\hline Concurrent tendinopathy present: no tendinopathy (ipsilateral side) & $34: 3$ \\
\hline $\begin{array}{l}\text { Symptomatic tendinopathy present contralateral side: } \\
\text { [Data unavailable] }\end{array}$ & $\begin{array}{l}10: 23 \\
{[4]}\end{array}$ \\
\hline Abnormal bursa present ipsilateral side: no bursa present ipsilateral side & $3: 34$ \\
\hline $\begin{array}{l}\text { Tendinopathy diagnosed on US contralateral side: no tendinopathy present } \\
\text { [Data unavailable] }\end{array}$ & $\begin{array}{l}26: 7 \\
{[4]}\end{array}$ \\
\hline $\begin{array}{l}\text { Average tendon thickness contralateral side to tear } \pm S D(\mathrm{~mm}) \\
\text { [Data unavailable] }\end{array}$ & $\begin{array}{l}6.61 \pm 2.30 \\
{[2]}\end{array}$ \\
\hline
\end{tabular}




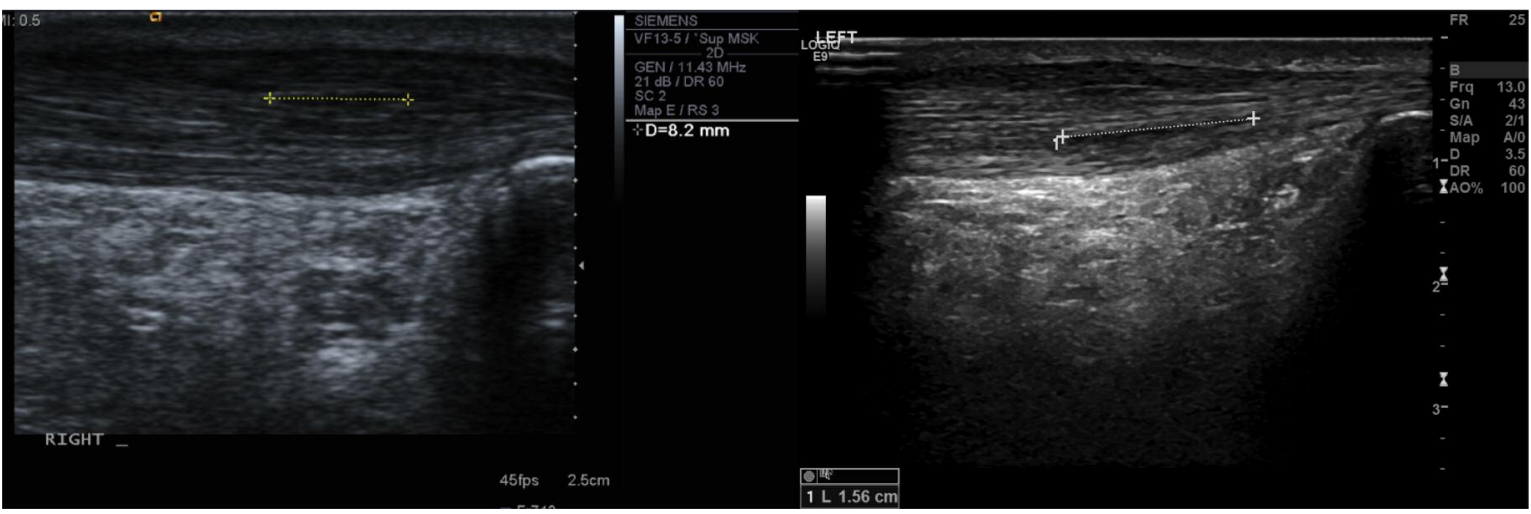

Figure 2. A small $82 \mathrm{~mm}$ linear intratendinous tear (left) and large $156 \mathrm{~mm}$ linear intratendinous tear (right) within the tendon without disruption of the overall tendon shape.

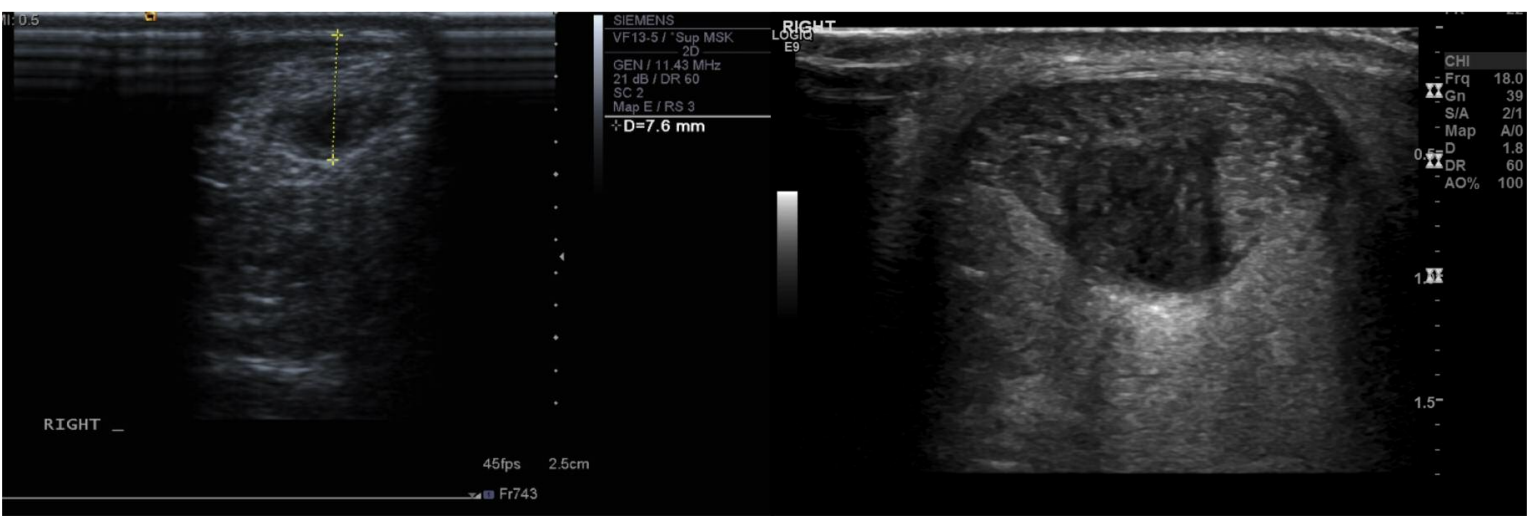

Figure 3. A small $76 \mathrm{~mm}$ oval intratendinous tear (left) and large oval intratendinous tear (right) situated within the tendon.

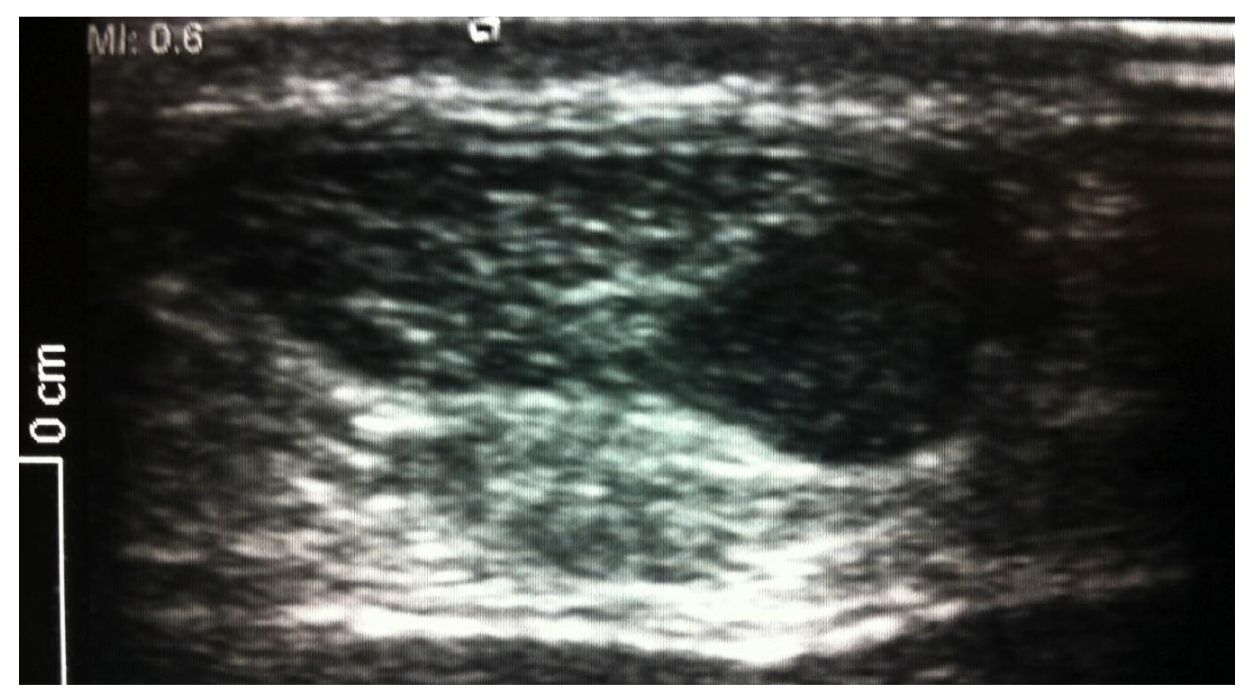

Figure 4. A partial tear of the Achilles tendon resulting in disruption of the fibres and the overall tendon shape, quite distinct from an intra-tendinous lesion.

in the tendon arising from the soleal and lateral gastrocnemius components (Figs. 1,7). This suggests, perhaps surprisingly based on the history of being unable to sprint, that it is more likely that the soleus fibres are being torn. It may be that despite having a high percentage of slow twitch muscle fibres, soleus is a greater force generator than gastrocnemius due to greater muscle volume and will therefore be strongly recruited at maximum effort. That said it must be considered that tear position may reflect injury mechanisms, possibly involving coronal plane rearfoot deviation during activity (e.g. pronation ten- 


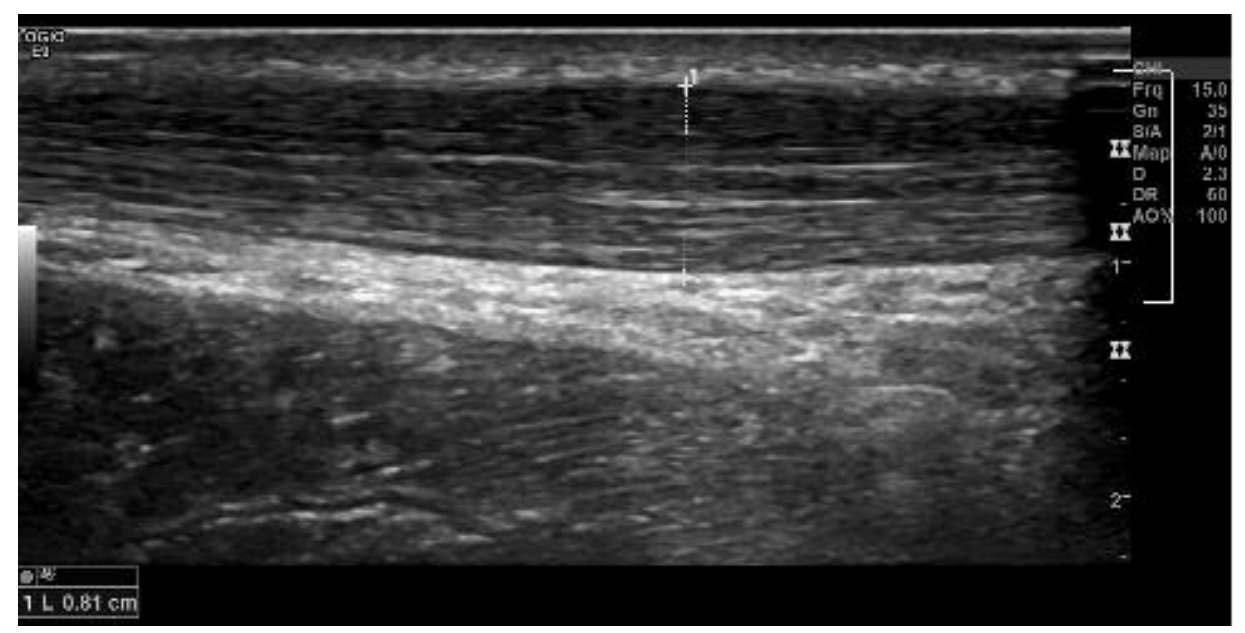

Figure 5. A classic midtendon bulge associated with tendinopathy measuring $8.1 \mathrm{~mm}$.
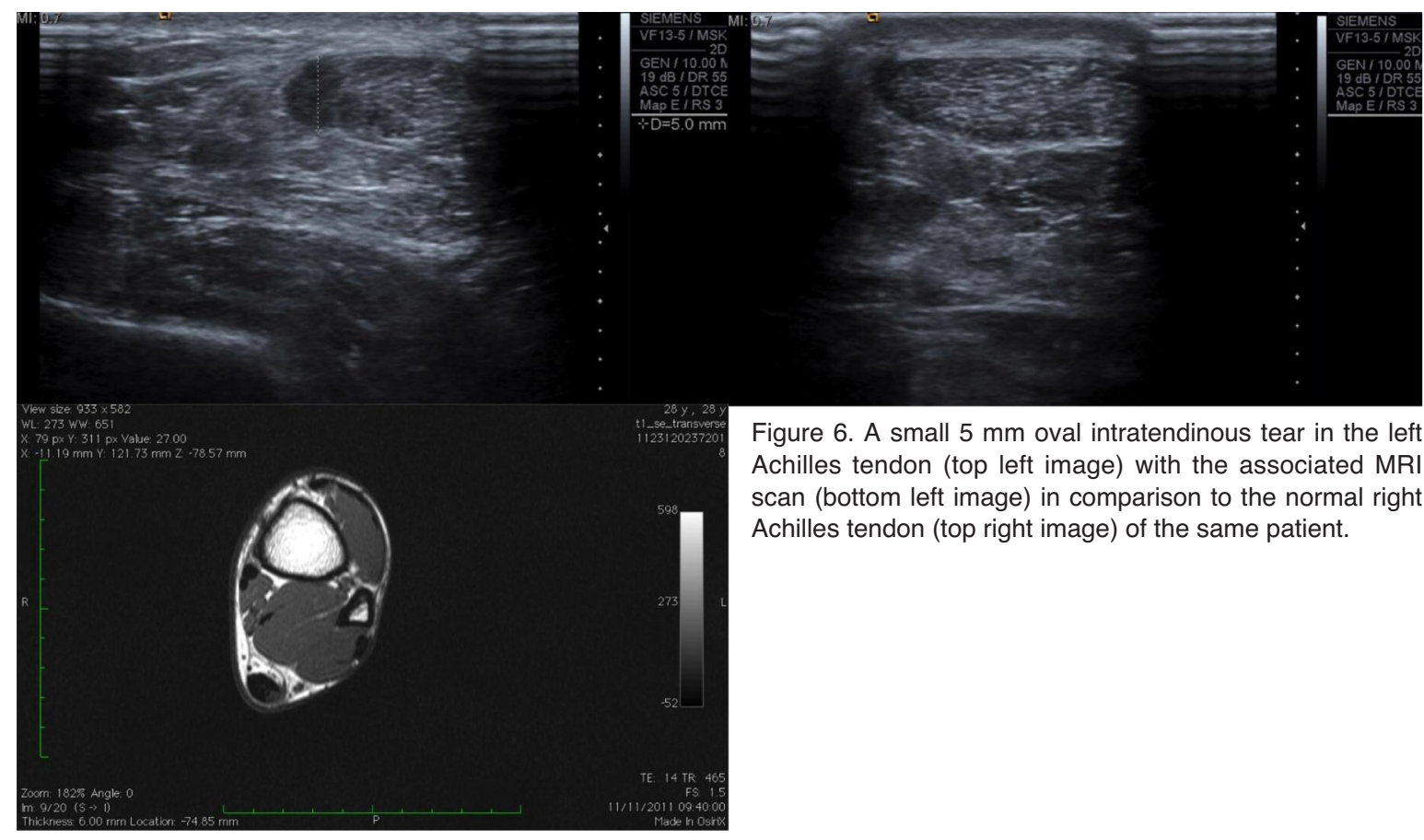

Figure 6. A small $5 \mathrm{~mm}$ oval intratendinous tear in the left Achilles tendon (top left image) with the associated MRI scan (bottom left image) in comparison to the normal right Achilles tendon (top right image) of the same patient.

sioning the medial tendon and fascia crura) or be extensions of focal areas of degeneration induced weakness. It may be that the fascicles (Fig. 7) may be failing causing the tear.

The course of the plantaris tendon being medial to, or invaginating, the Achilles tendon should also be considered in analysing this case series as it can become tendinopathic or develop symptoms which can mimic a tear in that it presents with focal medial pain $^{23}$. Alfredson (2011) has recently postulated plantaris to be a more important differential diagnosis than previously thought, due in part to differential material properties such as increased stiffness compared to the main Achilles tendon ${ }^{24}$. We observe plantaris to be present in nearly all subjects, except where there has been previous surgery, and to be variable in size and location, however its role - or otherwise - in the presentation of both tendinopathy and subtle tendon tears is unclear.

The influence of the paratenon may also be important, as it has been suggested that it may be the paratenon that is an initiating factor in tendinopathy. The paratenon is described as being in continuity with the crural fascia which is therefore influenced by the forces acting on the gastrocnemius ${ }^{25}$. This differs from the fascial band described by Saxena and Bareither which envelopes the flexor ligament ${ }^{26}$. Therefore, pain described on sprinting by subjects may be due to partenon pathology in some subjects, rather than the $\operatorname{ITT}^{14,25}$ 


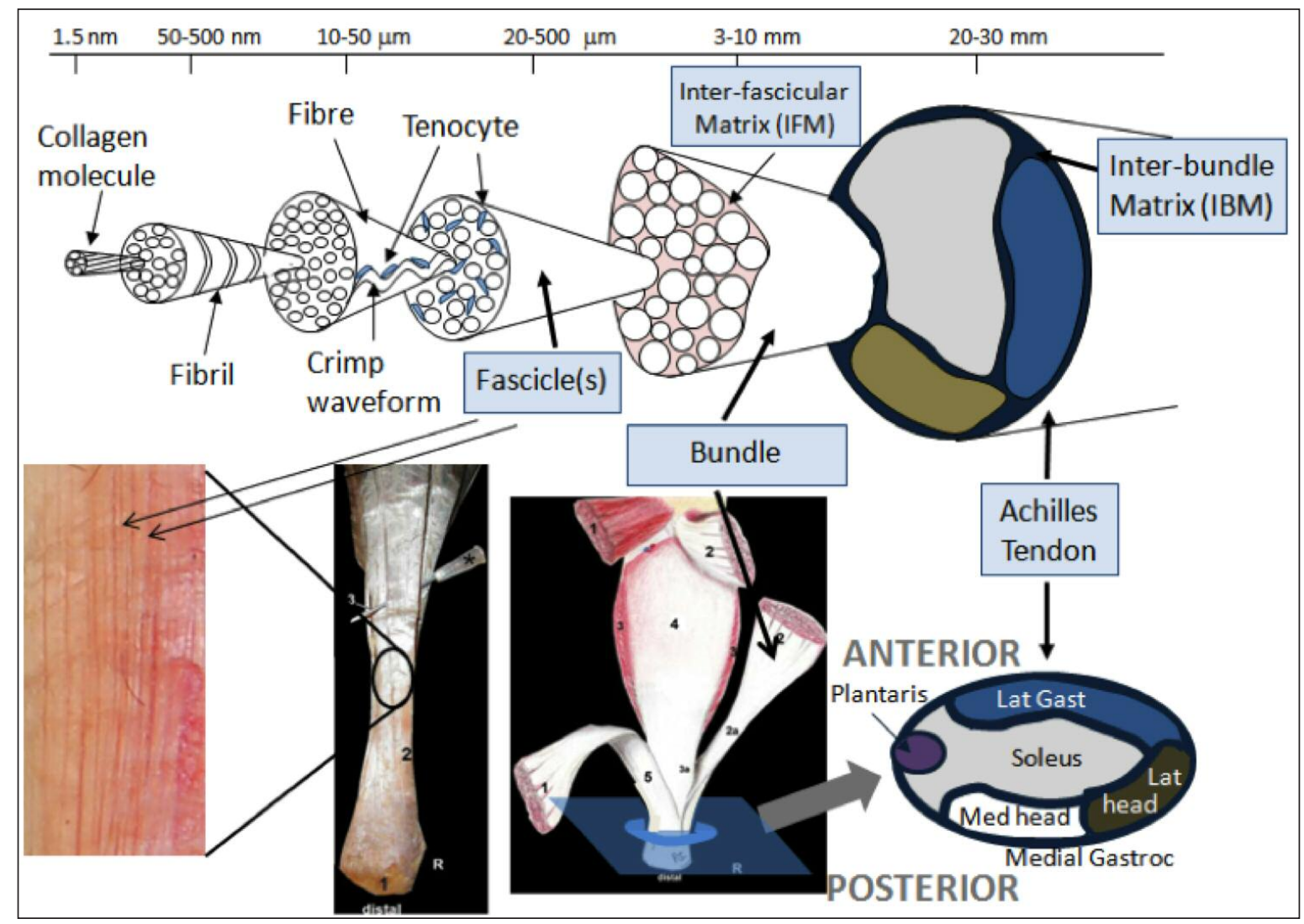

Figure 7. Schematic showing the hierarchical structure of the Achilles tendon designed with Professor Hazel Screen (QMUL). The second image, Szaro et al. (2009), from the left on the bottom shows a right Achilles tendon dissection with the number 2 marking the fibres from the lateral part of the medial head of gastrocnemius; the third image from the left (Szaro et al., 2009) shows number 1 as the medial head of gastrocnemius, 2 as the lateral head of gastrocnemius and 3 as soleus. The image on the bottom far right shows how the distribution of fibres fit together. The majority of ITTs was found to be arising from the soleal and lateral gastrocnemius components i.e. medial and anterior. The anterior-posterior and mediallateral positions of the series of tears are shown.

The ITTs are clearly distinct from partial tears, Alfredson et al. (2011) describing partial tears to be mostly dorsal (skin side) ${ }^{27}$. However, similarly to partial tears, high blood flow to and into that area can be seen on Power Doppler ${ }^{27}$. It is unclear why this occurs, as it might be thought that blood vessels would be disrupted, but it may be due to the healing process beginning or be a late element of the pathology as many tears were seen in the recalcitrant stage. The exact distance of the tear from the insertion was not always accurately recorded so this cannot be accurately compared with partial tears ${ }^{11,12}$. This is however an area for future research, along with histological tissue sampling results. This would allow the microscopic and macroscopic structure of an ITT to be established and compared to previous results from larger tears and ruptures. It is possible that similar markers of degenerative tendinopathy will be revealed, given the frequency of simultaneously diagnosed Achilles tendinopathy in the majority of patients and the findings of degenerative change when sampling from rupture sites ${ }^{23}$.

There was often a co-presentation of an ITT and Achilles tendinopathy, with thicker tendons and notable neovascularisation within the same tendon as the ITT.
This correlates with the literature on partial tears and their close association to tendinopathy ${ }^{10,28}$. However it should be noted that, unlike in Astrom et al. (1995) research on partial tears, there were three ITTs discovered without tendinopathy ${ }^{10}$. Twenty six subjects $(70 \%)$ with an ITT also had signs of tendinopathy in their contralateral Achilles tendon on ultrasound, although only $10 \%$ of these subjects were symptomatic on that side. These data suggest that the ITT is likely to be a feature of degenerative tendinopathy, but that it can also happen in isolation - perhaps with particular loading patterns or trauma to particular parts of the tendon. It could be speculated that these isolated ITTs may reflect a particular injury mechanism or susceptibility.

The use of high resolution ultrasonic diagnosis in expert hands allowed additional detail to be gained regarding the ITT in comparison to MRI, due to the dynamic evaluation and simultaneous confirmation of examination findings such as the area of maximum tenderness, as has been found in previous studies ${ }^{22}$. It may be that refinements of newer imaging techniques such as real-time sonoelastography or ultrasound tissue characterisation (UTC) will become useful for diagnosis in future - with anecdotal reports be- 
ing that UTC, due to its volumetric detail and within tendon contrast describes ITTs well29,30. Also, the use of power Doppler showed that there was an abnormal blood supply to the echo-poor area within the centre of the tendon, separate to the neovascularisation normally seen in tendinopathy. Finally, the presentation of ITTs to a specialist centre with a high volume of presenting patients enabled both identification and a multi-disciplinary approach to both the diagnosis and treatment of such a condition.

\section{Patient characteristics}

There were particular features of the patients diagnosed with an ITT. Seventy eight percent of subjects with an ITT was male, corresponding to the previous work showing Achilles tendinopathy to be more common in male subjects ${ }^{31}$. This may reflect a gender related predisposition but may also reflect sampling bias, and the higher proportion of males partaking in elite sport. Sixty eight per cent of patients with an ITT played an elite level of sport in comparison to only $14 \%$ with a mid-tendon tendinopathy (statistically significant) with the two most represented sports being football and sprinting athletics, again agreeing with the Achilles tendinopathy literature ${ }^{31}$. This is useful for clinicians, as a typical risk profile can be formulated. Further, the ITT group was younger, with an average age of 36.3 in the ITT group in comparison to 44.6 in mid-tendon tendinopathy group, which is statistically significantly less. It is unclear whether this related to the level of sport younger athletes tend to be associated with or if the pathology is more common in a younger population. However it again adds to the risk profile for an ITT. Only one asymptomatic ITT was documented, found in a patient with bilateral ITTs, unlike in the case of the interstitial tears described by Haims et al. (2000) where $7 \%$ of controls had tears ${ }^{16}$.

Although not detailed in the results above, our strong clinical impression is that many patients report subjects being able to train but not reach maximal loading. For example, subjects could frequently jog without discomfort but would be unable to push off at speed when wearing track spikes, due to a sharp pain in a particular point in their Achilles. Again, anecdotally, this point of maximum pain corresponded directly to where the ITT was detected on ultrasound. Further research is required to establish if these clinical observations can be confirmed and expanded on, which may enable a diagnosis to be made earlier and treatment initiated.

\section{Future research and limitations}

It is recognised that these diagnoses are based on a combination of clinical suspicion, clinical examination and confirmation by ultrasonography and additional imaging techniques such as MRI. MRI can complement the use of ultrasound due to imaging deeper and articular structures (Fig. 6). It was, however, our experience that MRI added little, if anything, to clinical assessment and ultrasound. Ideally macroscopic findings at surgery would confirm the findings on imaging, however our management approach is designed to minimise intervention and so patients rarely proceed to surgery. It would also be of interest to establish whether asymptomatic ITTs are found on both imaging and at surgery, especially for tendinopathy. Anecdotally, this is not something we have discovered. Research into suggested treatment techniques have already been undertaken ${ }^{32}$.

Despite this study being retrospective, the Authors did have the benefit of saved images and videos when compiling the data, along with the ultrasound reports. They were also all involved in the treatment and management of these patients and so we believe that this is a minor study limitation. As discussed above the optimum treatment requires further work. However, what would also be of interest would be the long-term imaging and macroscopic change of the highly vascularised echopoor area and the relation of these changes to subsequent symptoms.

\section{Conclusion}

Intratendinous tears are a clearly identifiable pathology of the Achilles tendon and should be considered in those presenting with pain in the Achilles. Currently the diagnosis can be made based on a combination of clinical suspicion and the characteristic ultrasound findings - with the acute onset, sharp pain on high load, a negative response to eccentric loading, relatively young presentation and elite athlete status apparently being key factors in the history and examination that should raise clinicians' index of suspicion. ITTs appear to be significantly more common in men and elite athletes although we have not collected exposure data and there is a close association with Achilles tendinopathy, although the subjects tend to be younger than those presenting with mid-tendon tendinopathy alone. It should however be noted that it is not necessary to have Achilles tendinopathy to be diagnosed with an ITT. The exact injury mechanism remains unclear but seems to have a sudden onset element. Future, prospective research is required to confirm these initial observations and consider optimal treatment in order to improve outcomes for Achillodynia.

\section{Conflict of interest}

$\mathrm{Dr}$.Morrissey is part funded by the NIHR/HEE Senior Clinical Lecturer scheme. This report presents independent research part-funded by the National Institute for Health Research (NIHR) CAT SCL-2013-04003. The views expressed are those of the Authors and not necessarily those of the NHS, the NIHR or the Department of Health.

\section{References}

1. Pierre-Jerome C, Moncayo V, Terk MR. MRI of the Achilles tendon: a comprehensive review of the anatomy, biomechan- 
ics, and imaging of overuse tendinopathies. Acta Radiol. 2010;51:438-454.

2. Asplund CA, Best TM. Achilles tendon disorders. BMJ. 2013;346:f1262.

3. Del Buono A, Chan O, Maffulli N. Achilles tendon: functional anatomy and novel emerging models of imaging classification. Int Orthop. 2013;37:715-721.

4. Khan KM, Cook JL, Kannus P, Maffulli N, Bonar SF. Time to abandon the "tendinitis" myth - Painful, overuse tendon conditions have a non-inflammatory pathology. BMJ. 2002;324: 626-627.

5. Rees JD, Stride M, Scott A. Tendons: time to revisit inflammation? Br J Sports Med. 2014;48:1553-1557.

6. Kannus P, Jozsa L. Histopathological changes preceding spontaneous rupture of a tendon. A controlled study of $891 \mathrm{pa}-$ tients. J Bone Joint Surg Am. 1991;73:1507-1525.

7. Hartgerink P, Fessell DP, Jacobson JA, van Holsbeeck MT. Full-versus partial-thickness Achilles tendon tears: Sonographic accuracy and characterization in 26 cases with surgical correlation. Radiology. 2001;220:406-412.

8. Allenmark C. Partial Achilles Tendon Tears. Clin Sports Med. 1992;11:759-769.

9. Schepsis $\mathrm{AA}$, Jones $\mathrm{H}$, Haas $\mathrm{AL}$. Achilles tendon disorders in athletes. Am J Sports Med. 2002;30:287-305.

10. Astrom M, Rausing A. Chronic Achilles Tendinopathy - A Survey of Surgical and Histolopatholgic Findings. Clin Orthop Relat Res. 1995:151-164.

11. Kalebo P, Goksor LA, Sward L, Peterson L. Soft-tissue Radiography, Computed-tomography, and Ultrasonography of Partial Achilles-Tendon Ruptures. Acta Radiologica. 1990;31 565-570.

12. Kalebo P, Allenmark C, Peterson L, Sward L. Diganostic value of ultrasonography in partial ruptures of the Achilles tendon. Am J Sports Med. 1992;20:378-381.

13. Szaro P, Witkowski G, Smigielski R, Krajewski P, Ciszek B. Fascicles of the adult human Achilles tendon - An anatomical study. Ann Anat. 2009;191:586-593.

14. Webborn N, Morrissey D, Sarvananthan K, Chan O. Acute tear of the fascia cruris at the attachment to the Achilles tendon: a new diagnosis. Br J Sports Med. 2015;49:1398-1403.

15. Ryan M, Wong A, Taunton J. Favorable Outcomes After Sonographically Guided Intratendinous Injection of Hyperosmolar Dextrose for Chronic Insertional and Midportion Achilles Tendinosis. AJR Am J Roentgenol. 2010;194:1047-1053.

16. Haims AH, Schweitzer ME, Patel RS, Hecht P, Wapner KL. MR imaging of the Achilles tendon: overlap of findings in symptomatic and asymptomatic individuals. Skeletal Radiol. 2000;29:640-645.

17. Padulo J, Oliva F, Frizziero A, Maffulli N. Muscle, Ligaments and Tendons Journal - Basic principles and recommendations in clinical and field science research: 2016 Update. MLTJ. 2016;6(1):1-5.

18. Fredberg U, Bolvig L, Andersen NT, Stengaard-Pedersen $\mathrm{K}$. Ultrasonography in evaluation of Achilles and patella tendon thickness. Ultraschall Med. 2008;29:60-65.

19. Ohberg L, Lorentzon R, Alfredson $\mathrm{H}$. Neovascularisation in Achilles tendons with painful tendinosis but not in normal tendons: an ultrasonographic investigation. Knee Surg Sports Traumatol Arthrosc. 2001;9:233-238.

20. Peers KHE, Brys PPM, Lysens RJJ. Correlation between power Doppler ultrasonography and clinical severity in Achilles tendinopathy. Int Orthop. 2003;27:180-183.

21. Comin J, Cook JL, Malliaras P, et al. The prevalence and clinical significance of sonographic tendon abnormalities in asymptomatic ballet dancers: a 24-month longitudinal study. Br J Sports Med. 2013;47:89-92.

22. Divani K, Chan O, Padhiar N, et al. Site of maximum neovascularisation correlates with the site of pain in recalcitrant midtendon Achilles tendinopathy. Man Ther. 2010;15:463-468.

23. Soila K, Karjalainen PT, Aronen HJ, Pihlajamaki HK, Tirman PJ. High-resolution MR imaging of the asymptomatic Achilles tendon: New observations. AJR Am J Roentgenol. 1999; 173:323-328.

24. Alfredson $\mathrm{H}$. Midportion Achilles tendinosis and the plantaris tendon. Br J Sports Med. 2011;45:1023-1025.

25. Stecco C, Cappellari A, Macchi V, et al. The paratendineous tissues: an anatomical study of their role in the pathogenesis of tendinopathy. Surg Radiol Anat. 2013;36:561-572.

26. Saxena A, Bareither D. Magnetic resonance and cadaveric findings of the "watershed band" of the achilles tendon. J Foot Ankle Surg. 2001;40:132-136.

27. Alfredson H, Masci L, Ohberg L. Partial mid-portion Achilles tendon ruptures: new sonographic findings helpful for diagnosis. Br J Sports Med. 2011;45:429-459.

28. Zafar MS, Mahmood A, Maffulli N. Basic Science and Clinical Aspects of Achilles Tendinopathy. Sports Med Arthrosc. 2009; 17:190-197.

29. Turan A, Tufan A, Mercan R, et al. Real-time sonoelastography of Achilles tendon in patients with ankylosing spondylitis. Skeletal Radiol. 2013;42:1113-1118.

30. van Schie HTM, Docking SI, Daffy J, Praet SE, Rosengarten $\mathrm{S}$, Cook JL. Ultrasound tissue characterisation, an innovative technique for injury-prevention and monitoring of tendinopathy. Br J Sports Med. 2013;47:e2-e.

31. Scott A, Huisman E, Khan K. Conservative treatment of chronic Achilles tendinopathy. CMAJ. 2011;183:1159-1165.

32. Chan O, Havard B, Morton S, et al. Outcomes of prolotherapy for intra-tendinous Achilles tears: A case series. MLTJ. 2016. 